Research Article

\title{
Environmental and antimicrobial properties of silver nanoparticles synthesized using Azadirachta indica Juss leaves extract
}

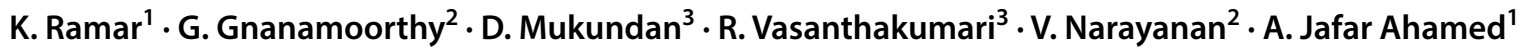

(c) Springer Nature Switzerland AG 2018

\begin{abstract}
This study employs a green, eco-friendly and convenient hydrothermal method for the synthesis of stable silver nanoparticles (Ag NPs) using medically beneficial Azadirachta indica A. Juss leaf extract as reducing as well as capping agent. Careful optimization of hydrothermal conditions leads to the formation of spherical Ag NPs of size 9-15 nm. Thus, synthesized NPs are characterized by spectroscopy and microscopy techniques, revealing the morphology and size the NPs. The chemical composition and functionality of the plant extract and NPs is studied using FTIR and EDS analysis. The photocatalytic activity of Ag NPs is demonstrated by decolourization of Rose Bengal under visible light. Ag NPs also show bactericidal activity against E. coli, K. pneumonia, S. epidermidis and S. pneumoniae.
\end{abstract}

\section{Graphical abstract}

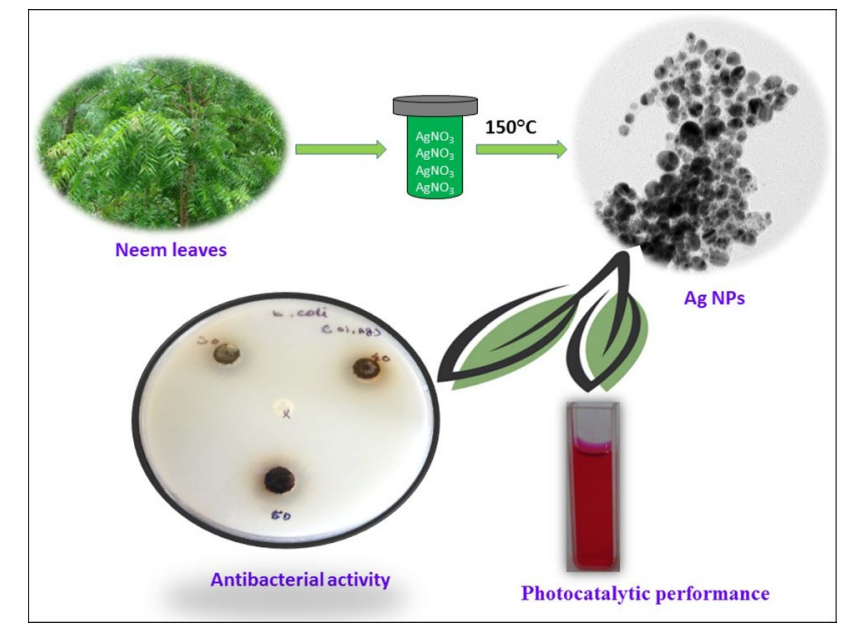

Keywords Hydrothermal · Green synthesis · Azadirachta indica A. Juss · Silver nanoparticles · Bactericidal activity

A. Jafar Ahamed, agjafar@yahoo.co.in | 1 PG and Research Department of Chemistry, Jamal Mohamed College (Autonomous), Tiruchirappalli, India. ${ }^{2}$ Department of Inorganic Chemistry, University of Madras, Guindy Campus, Chennai 600025 , India. ${ }^{3}$ Polymer Nano Technology Centre, B.S. Abdur Rahman University, Chennai, India. 


\section{Introduction}

Nanotechnology is attracting tremendous efforts of research because of the unique advantages it posses in various scenarios. The unique properties of metal nanoparticles with AgNPs and drags a lot of attention and used for many applications such as photocatalytic, electrical properties, optical, textile industry, pharmaceutical and bio-medical sciences in specific areas of anti-microbial, anti-viral and anti-fungal activities [1-10]. NPs can be synthesized by different chemical and physical methods. Many of the methods are reasonably expensive and potentially hazardous to the environment [11-13]. In contrast, the synthesis of NPs using microorganisms like (bacteria, fungi, algae) and plant extracts is non-toxic, and ecofriendly alternative to well-known chemical and physical procedures. The synthesis of NPs using plant extracts is simple procedures, time-reducing and fast compared to microorganisms. In addition, all parts of a plant including leaves, fruits, roots, seeds, and stems can be used for the synthesis of NPs [14-17]. On the other hand, plant materials contain chemical compounds like amino acids, proteins, polysaccharides, alkaloids, flavonoids and phenolic compounds etc., which can act as a reducing agents and stabilizing agents $[18,19]$.

According to Nair NC and Henry AN, Neem (Azadirachta indica A. Juss), a meliaceae family tree, is a hardy evergreen tree commonly found in all parts of India [18]. The Azadirachta indica A. Juss plant contained for triterpenoids, steroid, flavonoids, nimbin, salannin, phenolic compounds, and also the plant leaf extracts higher the properties of NPs like antibacterial activity [20-25]. In case of neem leaves commonly used for much medicinal purpose and wildly handling for tooth brush. Recently, Roy et al. [26] has been report for this same leaf and its inhibiting to the growth of microbes.

Dyes are a major class of synthetic organic compounds and natural pigments that are widely applied in various industries like paper, paint, plastic, leather, food, cosmetic, textile, printing and pharmaceutical industries $[27,28]$. Rose Bengal is an important fluorescein derivative dye widely used in textile industries whose molecular formula $\mathrm{C}_{20} \mathrm{H}_{4} \mathrm{Cl}_{4} \mathrm{I}_{4} \mathrm{O}_{5}$. It has severe toxic effects on the human health especially on corneal epithelium. This dye is very dangerous when it comes to contact with skin and causes itchiness, irritation, reddening and blistering. It also affects to eyes like inflammation, eye redness, itching etc. These synthetic dyes mixed with wastewater are directly discharged and pollute to plants, soil, water, and animals. There are several physical and chemical methods like coagulation, filtration, adsorption and reverse osmosis the removal of dye molecules and other water contaminants [29-32]. But there is a difficult to remove these dyes from water, because of their chemical stability. In recent times, nano-catalysts are widely used for the removal of dye molecules.

In this present work, a facile and ecofriendly method was developed to synthesize Ag NPs by adding Azadirachta indica A. Juss leaf extract as reducing and capping agent. The obtained Ag NPs were used to investigate the decolourization of RB dye under visible light irradiation and the results show good photocatalytic performance of these NPs. Further, these Ag NPs were used to determine by agar disc diffusion antimicrobial assay (Mueller-Hinton agar testing) against Gram-negative E. coli, K. pneumonia Gram-positive S. epidermidis and S. pneumoniae bacteria (Table 1).

\section{Experimental section}

\subsection{Materials}

Leaf of Azadirachta indica A. Juss were collected from B.S Abdul Rahman university campus and authenticated by Dr. S. Jayaraman, Director of Plant and Anatomy Research Centre, Chennai (Reg. No. PARC/2016/3239). Silver Nitrate $\left(\mathrm{AgNO}_{3}\right)$ (99.99\%) was procured from Sigma Aldrich, Mumbai. RB was obtained from Merck India Ltd. Deionized water has been used as the solvent throughout this experiment. Terephthalic acid (TA) and sodium hydroxide $(\mathrm{NaOH})$ used in the present study were procured from SRL fine Chemicals Ltd. Mumbai, India.
Table 1 The zone of inhibition (ZOI) for different bactericidal concentrations for Ag NPs and the positive control have chosen against $E$. coli, $K$. pneumoniae, S. epidermidis and S. pneumonia organisms

\section{SN Applied Sciences}

\begin{tabular}{llccc}
\hline $\begin{array}{l}\text { Concentration of sam- } \\
\text { ple }(\mu \mathrm{g} / \mathrm{mL})\end{array}$ & \multicolumn{4}{l}{ Zone of inhibition $(\mathrm{mm})$} \\
\cline { 2 - 5 } & E. coli & K. pneumonia & S. epidermidis & S. pneumonia \\
\hline 30 & $13.3 \pm 1.52$ & $13 \pm 1.0$ & $12.6 \pm 2.08$ & $14.6 \pm 0.57$ \\
40 & $12.3 \pm 2.08$ & $13 \pm 2.64$ & $14.6 \pm 3.05$ & $17.6 \pm 2.08$ \\
50 & $15.6 \pm 1.52$ & $12.6 \pm 2.08$ & $14.6 \pm 1.52$ & $15 \pm 2.0$ \\
Standard $10 \mu \mathrm{g}$ & $17.6 \pm 1.15$ & $16 \pm 2.64$ & $11.6 \pm 1.52$ & $11.6 \pm 1.52$ \\
\hline
\end{tabular}




\subsection{Preparation of leaves extract}

Fresh and healthy leaf of Azadirachta indica A. Juss were collected locally and rinsed thoroughly first with tap water followed by distilled water to remove all the dust and unwanted visible particles, cut into small pieces and shade-dried. About $5 \mathrm{~g}$ of leaves were weighed and transferred into $250 \mathrm{~mL}$ standard flask containing $100 \mathrm{~mL}$ distilled water and kept under magnetic stirring for $24 \mathrm{~h}$ at room temperature. The extracts were then filtered thrice through Whatman filter paper to remove particulate matter and thus obtained clear solutions were refrigerated in $100 \mathrm{~mL}$ Erlenmeyer flasks for further experiments.

\subsection{Hydrothermal preparation of the Ag NPs}

In a typical synthesis, $2 \mathrm{~mL}$ of aqueous extract of Azadirachta indica A. Juss leaf was added to $18 \mathrm{~mL}$ of $1 \mathrm{mM}$ aqueous $\mathrm{AgNO}_{3}$ solution. The solution mixture was transferred into a $100 \mathrm{~mL}$ Teflon-lined autoclave and heated at $150{ }^{\circ} \mathrm{C}$ for $3 \mathrm{~h}$ and then gradually cooled to room temperature. A block solid product at the bottom of the vessel indicated the formation of Ag NPs. The collected product was washed with distilled water several times and centrifuged to remove remnant starting materials in the reaction mixture, and finally stored in a desiccator for further use.

\subsection{Antimicrobial activity}

The antibacterial activity of the Ag NPs was determined by the diffusion method against Gram-negative E. coli, $K$. pneumonia, Gram-positive S. epidermidis and S. pneumonia bacteria on Mueller-Hinton Agar, according to the Clinical and Laboratory Standards Institute (CLSI). The media plates (MHA) were streaked with bacteria $2-3$ times by rotating the plate at $60^{\circ}$ angles for each streak to ensure the homogeneous distribution of the inoculums. After inoculation, discs (6 mm Hi-Media) loaded with $75 \mu \mathrm{L} /$ $\mathrm{mL}$, of the test sample was placed on the bacteria-seeded well plates using micropipettes. The plates were then incubated at $37^{\circ} \mathrm{C}$ for $24 \mathrm{~h}$. The inhibition zone around the well was measured and recorded. Amoxicillin (Hi-Media) was used as the positive controls against Gram-negative E. coli, K. pneumoniae Gram-positive S. epidermidis and S. pneumonia bacteria to compare the efficacy of the test samples.

\subsection{Photocatalytic activity study}

Photocatalytic was investigated by following the procedure mentioned in Gnanamoorthy et al. [33] and Ramar et al. [34]. The Photocatalytic performance of Ag NPs was testing by a Rose Bengal organic dye with using visible light irradiation, in a procedure: $20 \mathrm{mg}$ of Ag NPs was dispersed after $1 \mathrm{~mL}$ of dye with remaining $99 \mathrm{~mL}$ of water also added. Finally, this suspension was stirred in $5 \mathrm{~min}$ in dark medium after lights on and further samples were collected in different time intervals with monitored by using UV-Vis spectrophotometer.

\subsection{Hydroxyl ('OH) radical detection}

Terephthalic acid (TA) was used in order to find out the generation of the main active species is hydroxyl $(\mathrm{OH}) \mathrm{rad}-$ icals during the photoreaction process. To determine the production of $\mathrm{OH}$ radicals, $0.5 \mathrm{mg}$ of the photocatalyst was added to a $10 \mathrm{~mL}$ mixture of TA solution $(0.415 \mathrm{mg})$ dissolved in $\mathrm{NaOH}$ solution $(0.4 \mathrm{mg})$ and magnetic stirred for $30 \mathrm{~min}$. After the production of $\mathrm{OH}$ radicals under UV-visible light (30 $\mathrm{min}$ ) irradiation, the reacted solution was centrifuged and then monitored by Fluoromax-4 Spectrophotometer. TA readily reacts with $\mathrm{OH}^{*}$ hydroxyl radicals to generate highly fluorescent 2-hydroxyterephthalic acid (TAOH) which emits fluorescence around $461 \mathrm{~nm}$ on excitation at $350 \mathrm{~nm}$.

\subsection{Characterization}

Synthesis of NPs and their photocatalytic activity were monitored with the help of a UV-visible, single beam spectrophotometer (Jasco V-770). Powder X-ray diffraction (PXRD) was carried out using Bruker D8 diffractometer $[\lambda$ $(\mathrm{Cu}-\mathrm{Ka})=1.54 \AA ̊$ ] . Fourier-Transform Infrared Spectroscopy (FTIR) results were obtained from Jasco 6300 spectrometer (ATR mode) in the range of $400-4000 \mathrm{~cm}^{-1}$. Field emission scanning electron microscopy (FESEM) images were recorded using an Ultra 55 Carl Zeiss instrument with an operating voltage of $10 \mathrm{kV}$. Samples for the FESEM analysis were mounted on a stub using a conductive carbon tape. Transmission electron microscopy (TEM) and selected area electron diffraction (SAED) images were recorded using an FEI Technai G220 STEM instrument operated at an acceleration voltage of $200 \mathrm{kV}$. The hydrodynamic size distributions of NPs were analysed using dynamic light scattering (DLS) instrument (Zetasizer Nano-S90). The photoluminescence (PL) emission and excitation spectra were recorded on a Horiba Jobin-Yvon model FL3-22 Fluoromax-4 Spectrophotometer.

\section{Results and discussion}

\subsection{Powder X-ray diffraction (PXRD)}

The crystalline nature of Ag NPs was confirmed by powder X-ray diffraction (PXRD) analysis. Figure 1a shows a typical PXRD pattern of Azadirachta indica A. Juss leaf extract. The 


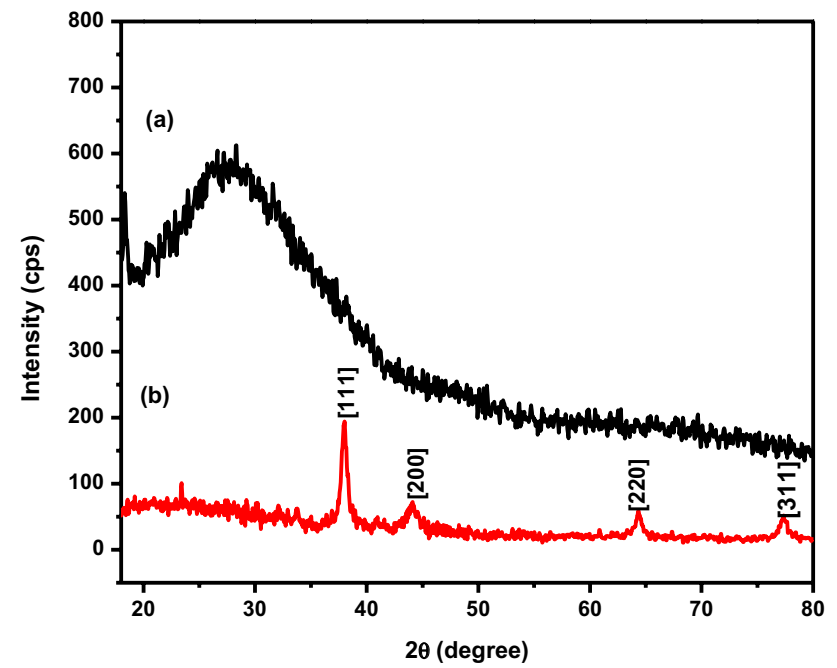

Fig. 1 PXRD pattern of a Azadirachta indica A. Juss leaf extract and b synthesized Ag NPs

broad hump peak appearing at about $2 \theta=28^{\circ}$ refers to the presence of biomolecules like amino acids, triterpenoids, steroid, flavonoids, nimbin, salannin, alkaloids, and phenolic and also it indicated the absence of Au NPs in the leaf extract. The PXRD pattern (Fig. 1b) showed four major peaks at $2 \theta=37.97^{\circ}, 44.12^{\circ}, 64.34^{\circ}$, and $77.39^{\circ}$ corresponding to the indices of (111), (200), (220) and (311) are in good agreement with (JCPDS 04-0783) which confirmed that the hydrothermally synthesized Ag NPs are nanocrystalline with the fcc crystal structure. However, secondary small intensity peaks seen in the PXRD patterns may be due to biomolecules of the Azadirachta indica A. Juss leaf extract that were binding to NPs surface [35]. The average crystallite sizes of the obtained Ag NPs were calculated by using the Debye-Scherrer formula (Eq. 1).

$\mathrm{D}=\mathrm{K} \cdot \lambda / \beta \cdot \cos \theta$

where, $K$ is the shape factor, $\lambda$ is the wavelength of the incident beam ( $1.54 \AA$ ) , $\beta$ is the broadening of the diffraction angle measured in radians at half width at maximum intensity (FWHM), $\theta$ is the Bragg's angle for the studied peak and $D$ is the diameter of the crystallite size. The PXRD plane (111) was chosen to calculate the crystallite size for Ag NPs and the average crystallite sizes were found to be around $21 \mathrm{~nm}$. The PXRD result was in agreement with SAED results, supporting the high crystalline nature and crystallite size of the nanoparticles.

\subsection{Fourier transform infrared spectroscopy (FTIR)}

The dual role of the plant extract as a reducing and capping agent of the present functional groups on the NPs surface was confirmed by FTIR analysis as shown

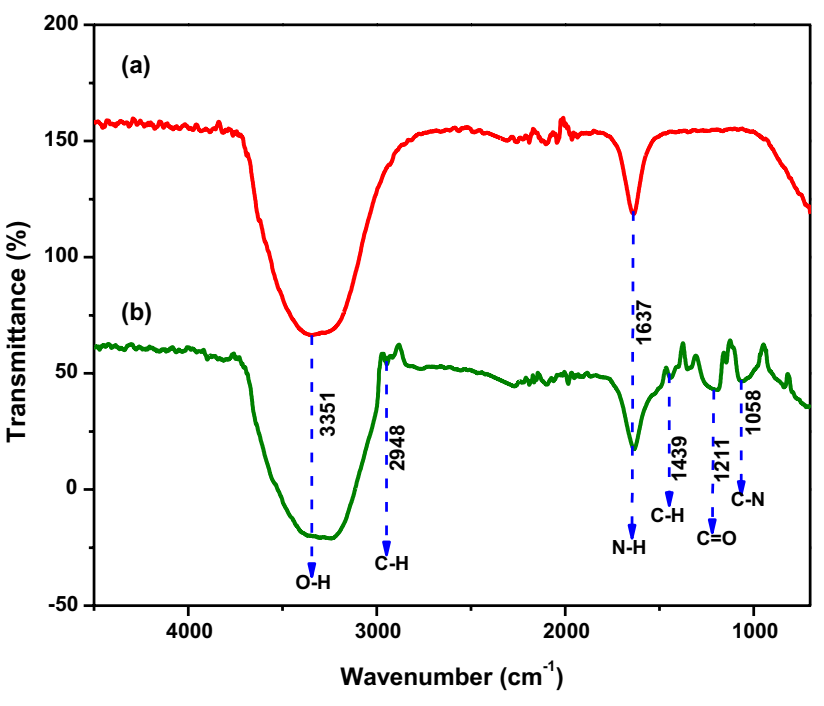

Fig. 2 FT-IR spectra of $\mathbf{a}$ synthesized Ag NPs and $\mathbf{b}$ Azadirachta indica A. Juss leaf extract

in Fig. 2. The IR spectrum of Ag NPs (Fig. 2b) showed absorption bands located at 3351, 2948, 1637, 1439, 1211 and $1058 \mathrm{~cm}^{-1}$ respectively, which are corresponding to the $\mathrm{O}-\mathrm{H}$ stretching, $\mathrm{C}-\mathrm{H}$ stretching, $\mathrm{N}-\mathrm{H}$ bending, $\mathrm{C}-\mathrm{H}$ bending, $\mathrm{C}=\mathrm{O}$ stretching, $\mathrm{C}-\mathrm{N}$ stretching, with different functional groups like amines, carboxylic acids, aldehydes, ketones, alcohols, and aliphatic amines adsorbed on the surface of NPs. The same pattern is also observed in Fig. 2a as a result of the Azadirachta indica A. Juss leaf extract, with bands at 3351 and $1637 \mathrm{~cm}^{-1}$. The functional group may be due to binding the surface of silver ions by stabilizing the NPs as capping agents [36].

\subsection{UV-visible diffuse reflectance spectroscopy}

As shown in UV-Visible diffuse reflectance spectra (UV-Vis DRS), the SPR bands centered at $442 \mathrm{~nm}$ confirms the formation of Ag NPs as shown in Fig. 3a. The appearance of the peak is due to the size dependent quantum mechanical phenomenon called Surface Plasmon Resonance (SPR). This effect because influential when the De-Broglie wavelength of the valence electrons equal or less than the size of the particle. The UV-Vis DRS spectra of the leaf extract shows a band at $264 \mathrm{~nm}$ arising due to $n-\pi^{*}$ transition [37]. A plot of (hu) versus photon energy (hu) of Ag NPs is shown in Fig. 3b. The Energy band gap (Eg) of NPs was calculated according to the reported Eq. (2).

$\alpha=\mathrm{A}\left(\mathrm{h} v-\mathrm{E}_{\mathrm{g}}\right)^{\mathrm{n} / 2} / \mathrm{h} v$

\section{SN Applied Sciences}




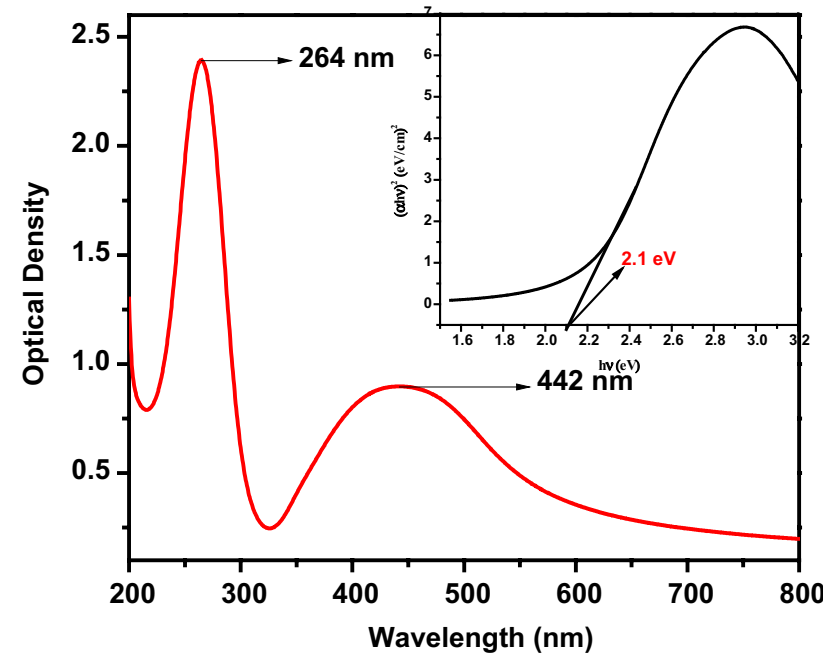

Fig. 3 a UV-Vis DRS spectra of synthesized Ag NPs. Inset the plot $\mathbf{b}$ of transformed $(\mathrm{ahu})^{1 / 2}$ versus the photon energy (hu)

where, $a$ is the absorption coefficient, $h v$ is the photon energy, $A$ is a constant, and $\mathrm{Eg}$ is band gap energy, respectively. Figure $3 \mathrm{~b}$ shows that the band gap of Ag NPs is $2.1 \mathrm{eV}$

\subsection{Field emission scanning electron microscopy- energy dispersive spectroscopy}

FE-SEM was used to understand the morphology and size of Ag NPs as shown in Fig. 4a-c. Ag NPs were spherical in shape, with size ranging from 15 to $35 \mathrm{~nm}$. It is interesting to note that almost all the Ag NPs are equally distributed and surrounded by polyphenol layer of biomolecules, indicating that Ag NPs were capped and dispersed by the biomolecules existing in Azadirachta indica A. Juss leaf extract. The FE-SEM results seem to be consistent with the TEM results.

EDS analysis also confirms the presence of a strong peak of elemental composition silver (69.34 wt\%), oxygen (10.18 wt\%), carbon (14.37 wt\%) and a weak nitrogen (6.11 wt\%) peak as shown in Fig. 4d. The oxygen, carbon and nitrogen peaks might be due to the presence of biomolecules binding to the surface of hydrothermally synthesized Ag NPs [38].

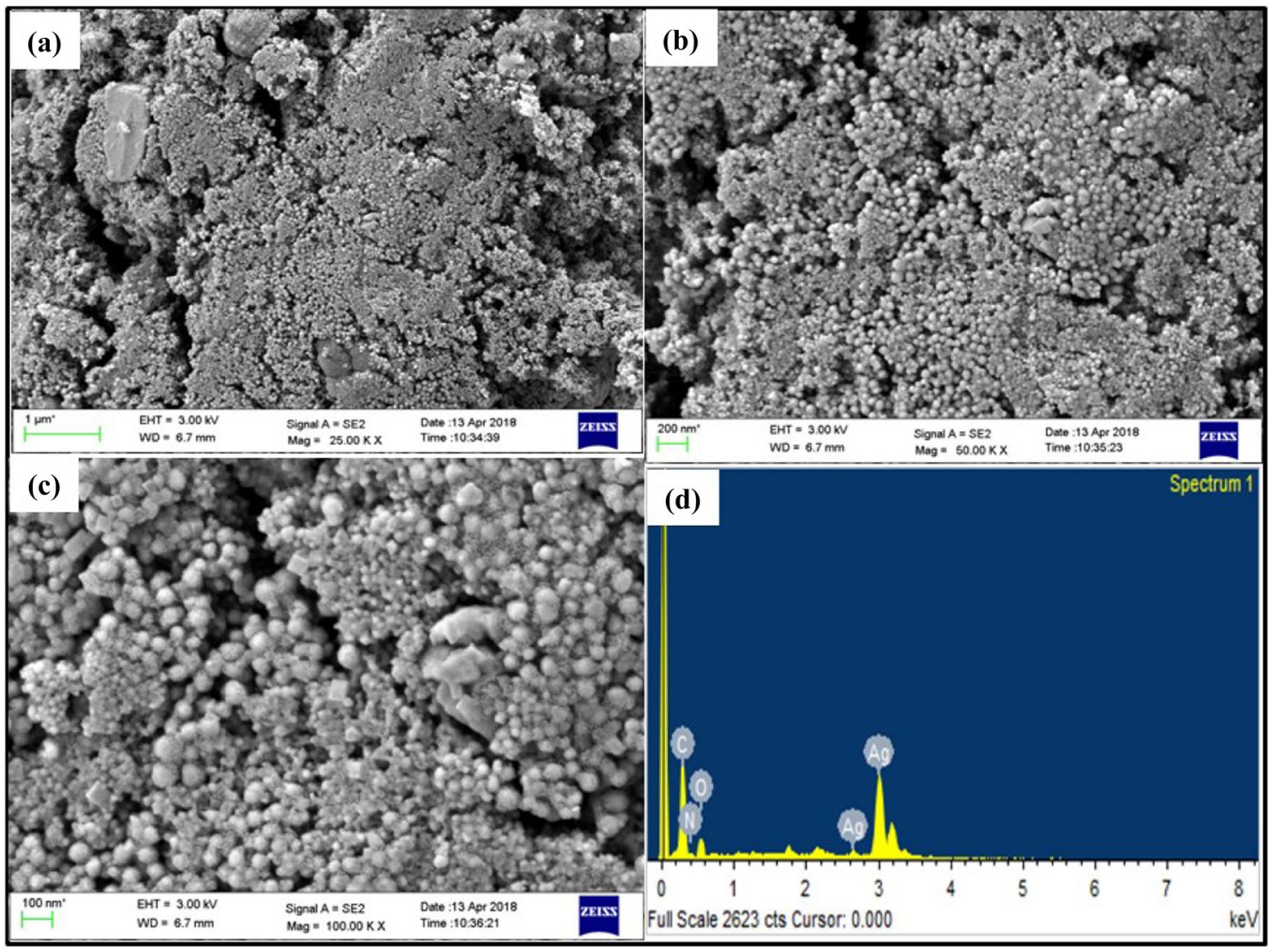

Fig. 4 a-d FESEM images of synthesized Ag NPs at different magnifications and $\mathbf{d}$ EDS spectrum of Ag NPs 


\subsection{Transmission electron microscopy (TEM) and dynamic light scattering (DLS)}

The surface morphology and size formation of hydrothermally synthesized Ag NPs using Azadirachta indica A. Juss leaf extract were analyzed using TEM images as shown in Fig. $5 a-e$. It can be clearly seen from the image that the Ag NPs were found to be spherical in shape with size ranging from 9 to $15 \mathrm{~nm}$, which are similar to FESEM observations. The various polyphenolic compounds present in the Azadirachta indica A. Juss leaf extract could be responsible for the formation of spherical nanoparticles. The Fig. 5e lattice fringe width of $0.25 \mathrm{~nm}$ corresponds to (111) facets of the fcc crystal structure. The SAED analysis for silver nanoparticles showed ring like pattern indicating the crystalline structure of Ag NPs as shown in Fig. $5 f$ [39].

DLS is a technique used to investigate the particle size distribution profile and the curve obtained by scanning suspension of Ag NPs. Figure 6 show the average diameter of the particles as 10-12 nm for Ag NPs. This DLS particle size distribution is in good agreement with the values observed by TEM.

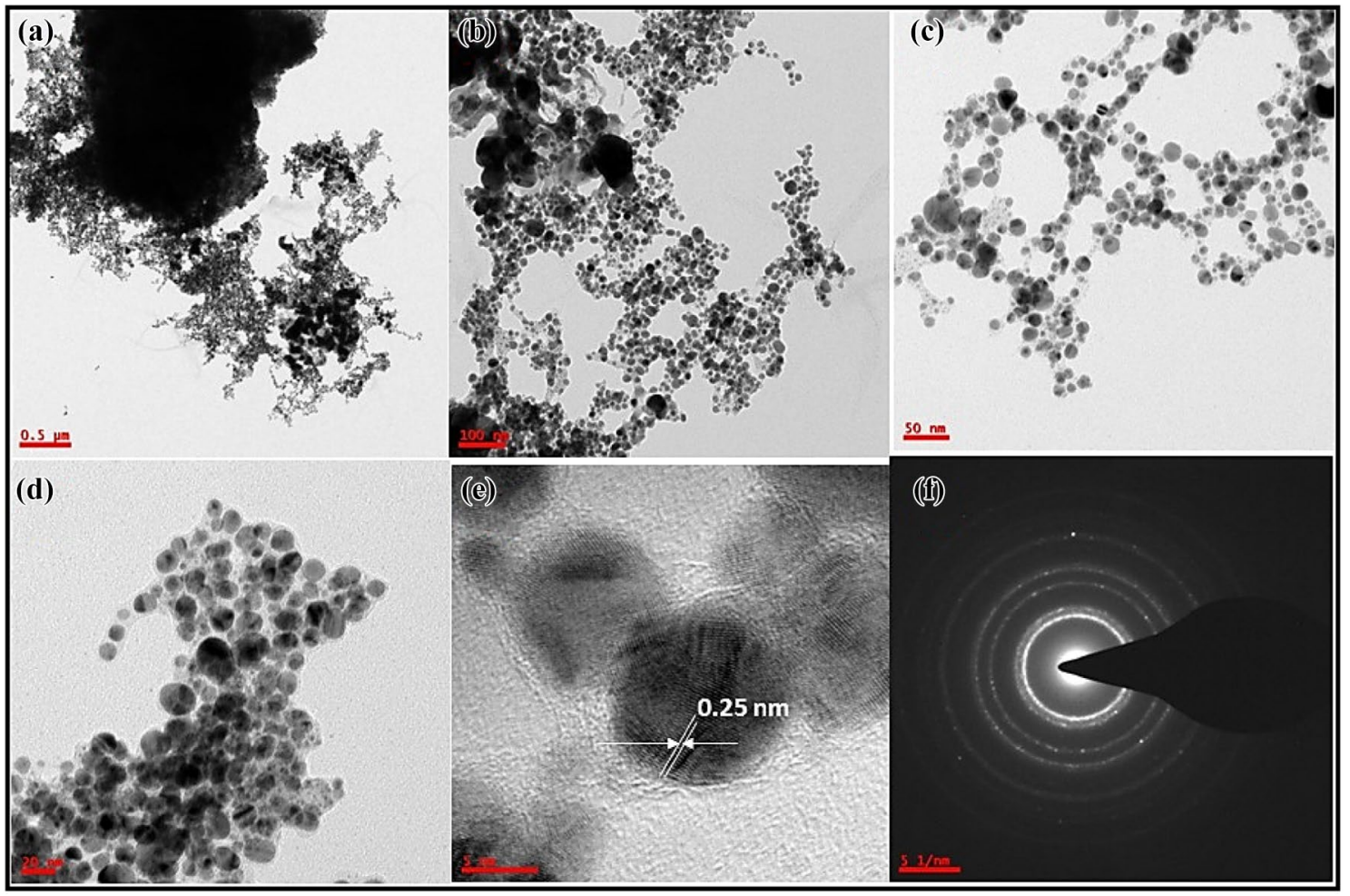

Fig. 5 TEM micrographs (a-d), lattice fringes (e) and SAED pattern (f) of Ag NPs

Fig. 6 Size distribution of $\mathrm{Ag}$ NPs produced in Azadirachta indica A. Juss leaf extract measured by DLS method
Size Distribution by intensity

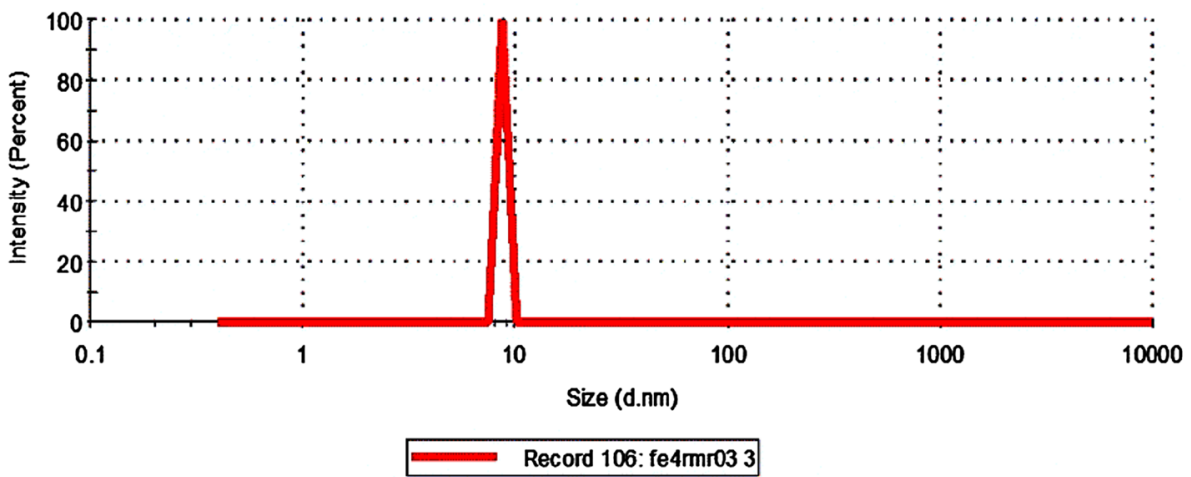




\subsection{Photocatalytic performance}

To investigate the photocatalytic activity of Ag NPs for the decolourization of Rose Bengal (RB) under visible light irradiation, first we performed a blank experiment in the absence of catalysts and visible light Fig. 7a. As shown in Fig. 7b, in the presence of Ag NPs, the absorbance by RB at $547 \mathrm{~nm}$ completely disappeared within $35 \mathrm{~min}$ with the increasing irradiation time. A linear relationship was obtained on plotting $\ln \left(C_{t} / C_{o}\right)$ versus time Fig. 7c. The intrinsic reaction rate constant was calculated from the slope of the straight line and found to be $\mathrm{R}=0.9854 \mathrm{~min}^{-1}$ and slope $=0.0819 \mathrm{~min}^{-1}$ respectively.

\subsection{Mechanism on enhancement of photo decolourization activity}

Terephthalic acid (TA) is used as a probe molecule to study $\mathrm{OH}^{*}$ radicals by photoluminescence $(\mathrm{PL})$ technique. The fluorescence emission peak at $461 \mathrm{~nm}$ from TOHA solution was found and then continuously recorded the generation of $\mathrm{OH}^{\circ}$ using Ag NPs until 240 min as shown in Fig. 8. Using Ag NPs the generation of $\mathrm{OH}$ radicals as well as photocatalytic activity is improved.

A possible photocatalytic mechanism of Ag NPs by using Rose Bengal is proposed in Fig. 9. According to the detailed study carried out by Chen et al. [40]. The influence of surface plasmonic resonance on the photocatalytic

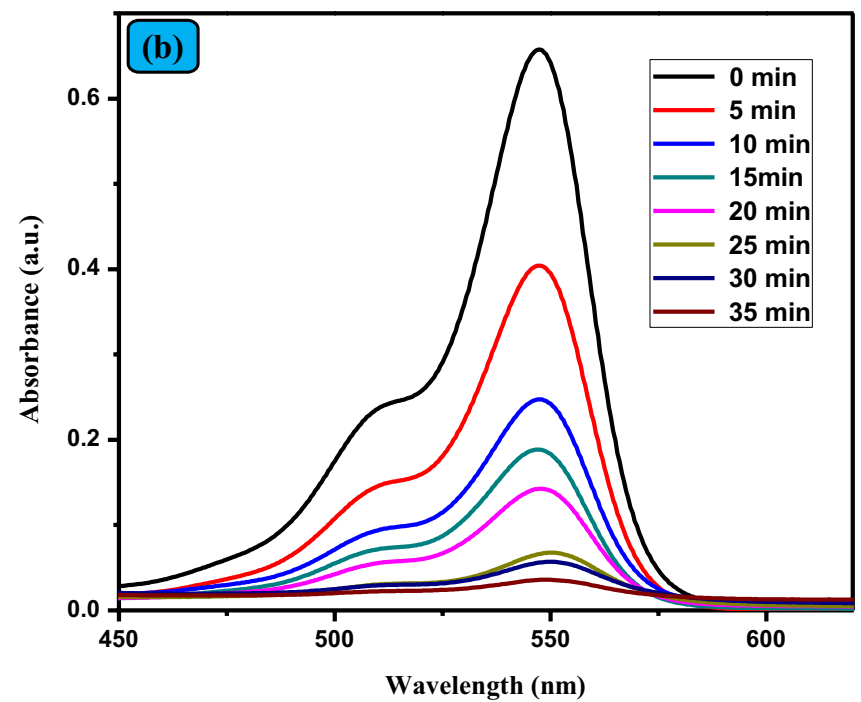

Wavelength (nm)
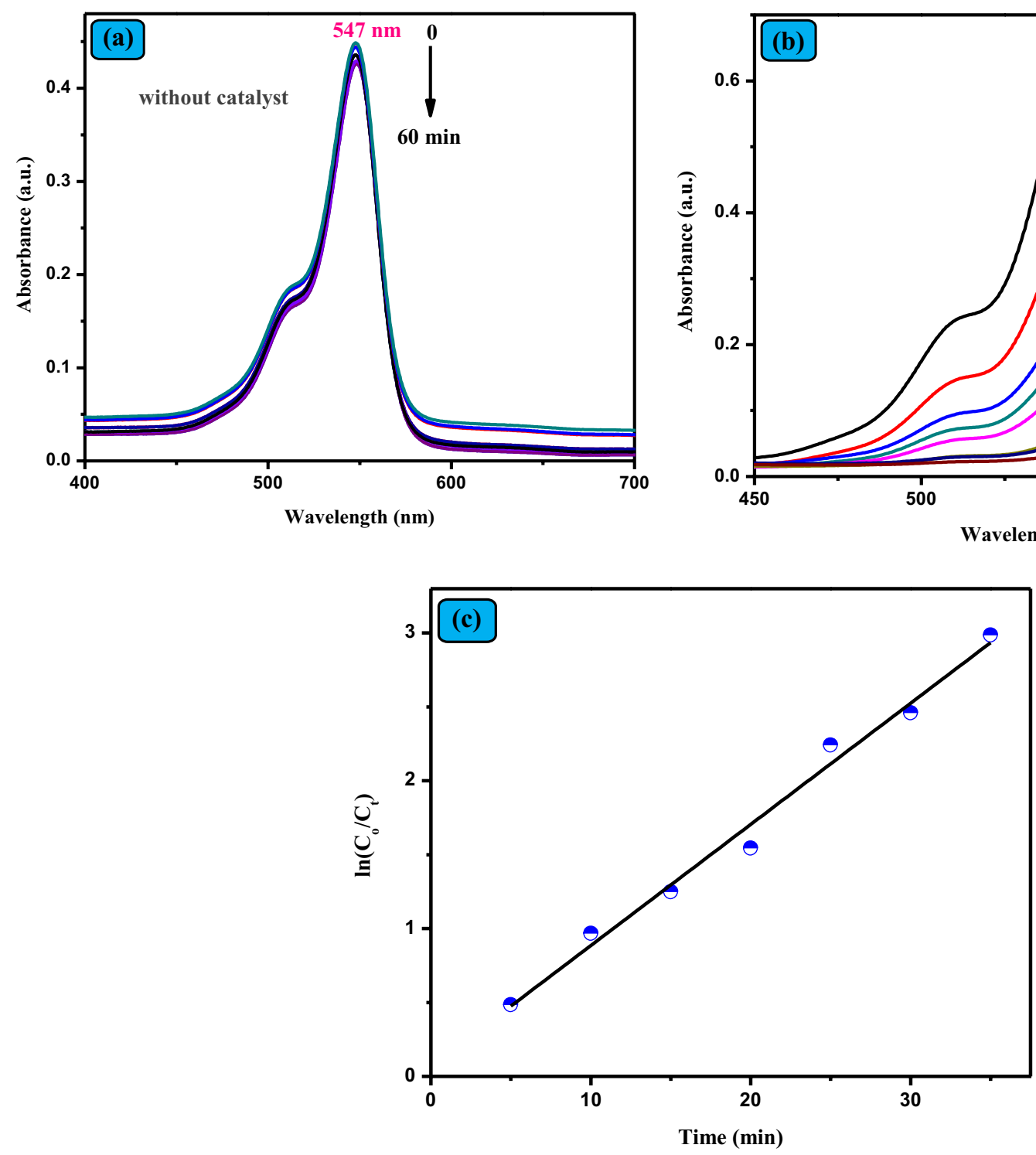

Fig. 7 a UV-visible spectra of the RB aqueous solution (without catalyst), b Time-dependent UV-visible absorption spectra for the degradation of RB with the catalyst in the presence of synthesized Ag NPs. c Plots of $\ln \left(C_{o} / C_{t}\right)$ versus the time 


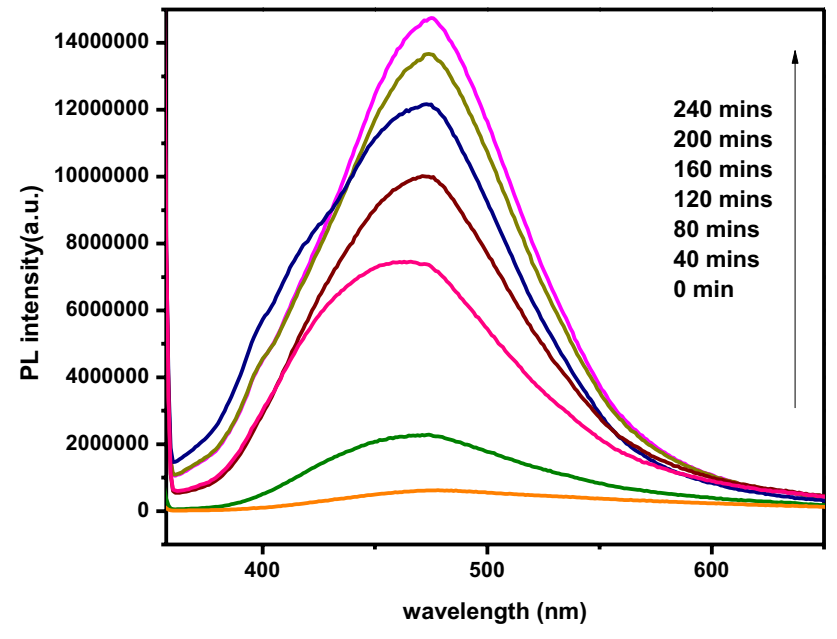

Fig. $8 \mathrm{OH}$-trapping PL spectra of Ag NPs in solution of terephthalic acid at room temperature

performance under visible light illumination has been explained by charge transfer mechanism. In the charge transfer mechanism, the plasmonic resonance excites the electrons in the Ag nanoparticles, which are transferred to the conduction band, leaving a "plasmonic hole" in the metal nanoparticle. A half-filled band occurs in materials consisting of atoms, which contain only one valence electron per atom. Most highly conducting metals including copper, gold and silver satisfy this condition [41, 42]. According to this mechanism, it is not necessary to excite the Ag NPs to produce charge carriers, which are produced in the metal nanoparticle under illumination with light corresponding to the SPR excitation wavelength and it has been found that these plasmonic charge carriers can participate in several redox reactions.

To more explain these photocatalytic observations, we propose a charge transfer mechanism as illustrated in
Fig. 9. When Ag nanoparticles absorb visible irradiation, the surface electrons of the $4 \mathrm{~d}$ band can be excited to the $5 s p$ states due to SPR effect [43-46]; these SPR effect by Ag NPs efficiently generated electrons and holes. The electrons are readily accepted by the oxygen $\left(\mathrm{O}_{2}\right)$ molecules to form superoxide radicals $\left._{2}\right)$ which attack and promote the decolourization of RB dye molecules. Also, the holes generated in the $4 \mathrm{~d}$ orbital and react with adsorbed $\mathrm{H}_{2} \mathrm{O}$ to produce hydroxyl radicals $(\mathrm{OH})$ which attack the $\mathrm{RB}$ dye molecules. In addition to the decolourization of the dyes by the radicals, the holes generated in the $4 \mathrm{~d}$ orbital of the Ag NPs capture electrons from the adsorbed dye molecule leading to further decolourization of the RB dye. These activated radical species $\left(\mathrm{OH}^{\prime}, \mathrm{O}_{2}\right)$ are responsible for $\mathrm{RB}$ decolourization and the generation of transitional products $\mathrm{CO}_{2}, \mathrm{H}_{2} \mathrm{O}$. Thus, the Ag NPs are known for absorption of whole of the visible spectrum due to SPR effect and the interband transition of $4 \mathrm{~d}$ electrons to $5 \mathrm{sp}$ band.

\subsection{Antimicrobial activities}

The zone of inhibition values are obtained for the hydrothermally synthesized Ag NPs against two different micro organisms like Gram-negative E. coli, K. pneumoniae Grampositive S. epidermidis and S. pneumonia bacteria. The antibacterial activities of Ag NPs are more efficient against Gram-positive S. epidermidis and S. pneumonia bacterial than the Gram-negative E. coli, K. pneumoniae bacteria. Different sensitivities of Gram-positive and Gram-negative bacteria against the Ag NPs is because say for example, E. coli, K. pneumonia has a more negatively charged and more rigid surface than S. epidermidis and S. pneumonia bacteria.

In addition to the Gram-negative bacteria cell wall is composed of a thin lipoprotein layer and a single layer of peptidoglycan. The peptidoglycan is placed within the
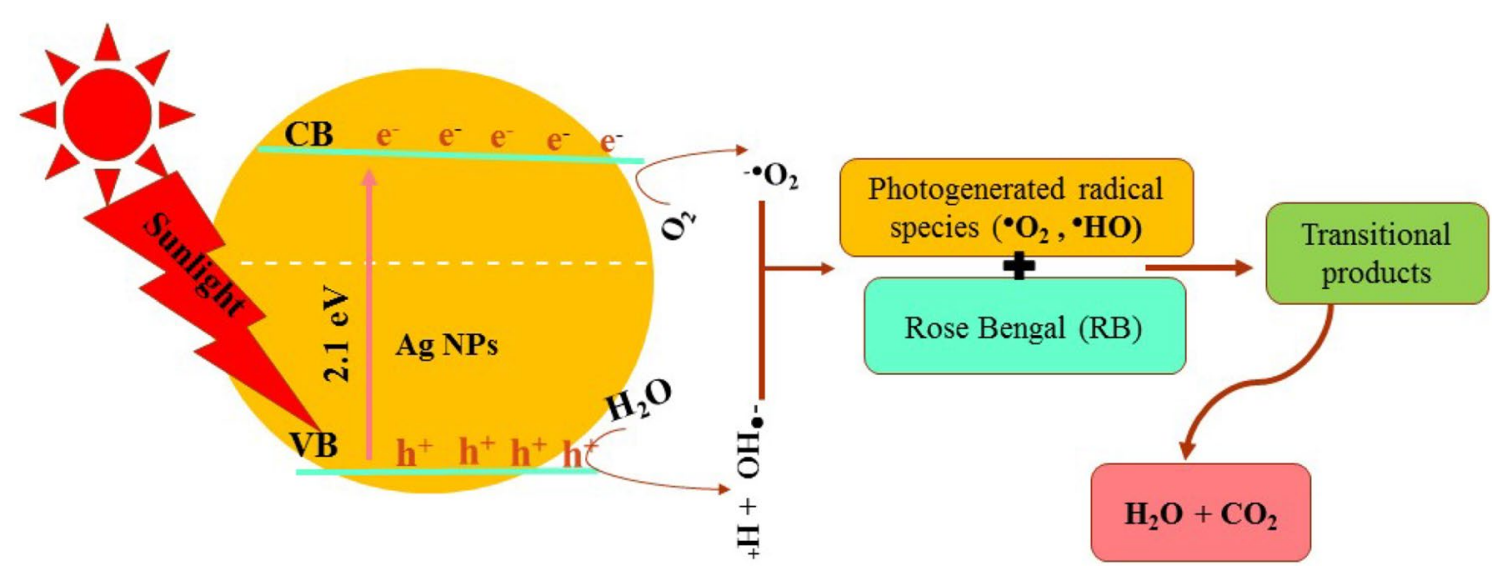

Fig. 9 Schematic representation of the photocatalytic mechanism of Ag NPs under visible light irradiation 
Fig. 10 Antibacterial activity of Azadirachta indica A. Juss leaf extracts Ag NPs against E. coli, K. pneumonia, S. epidermidis and S. pneumonia

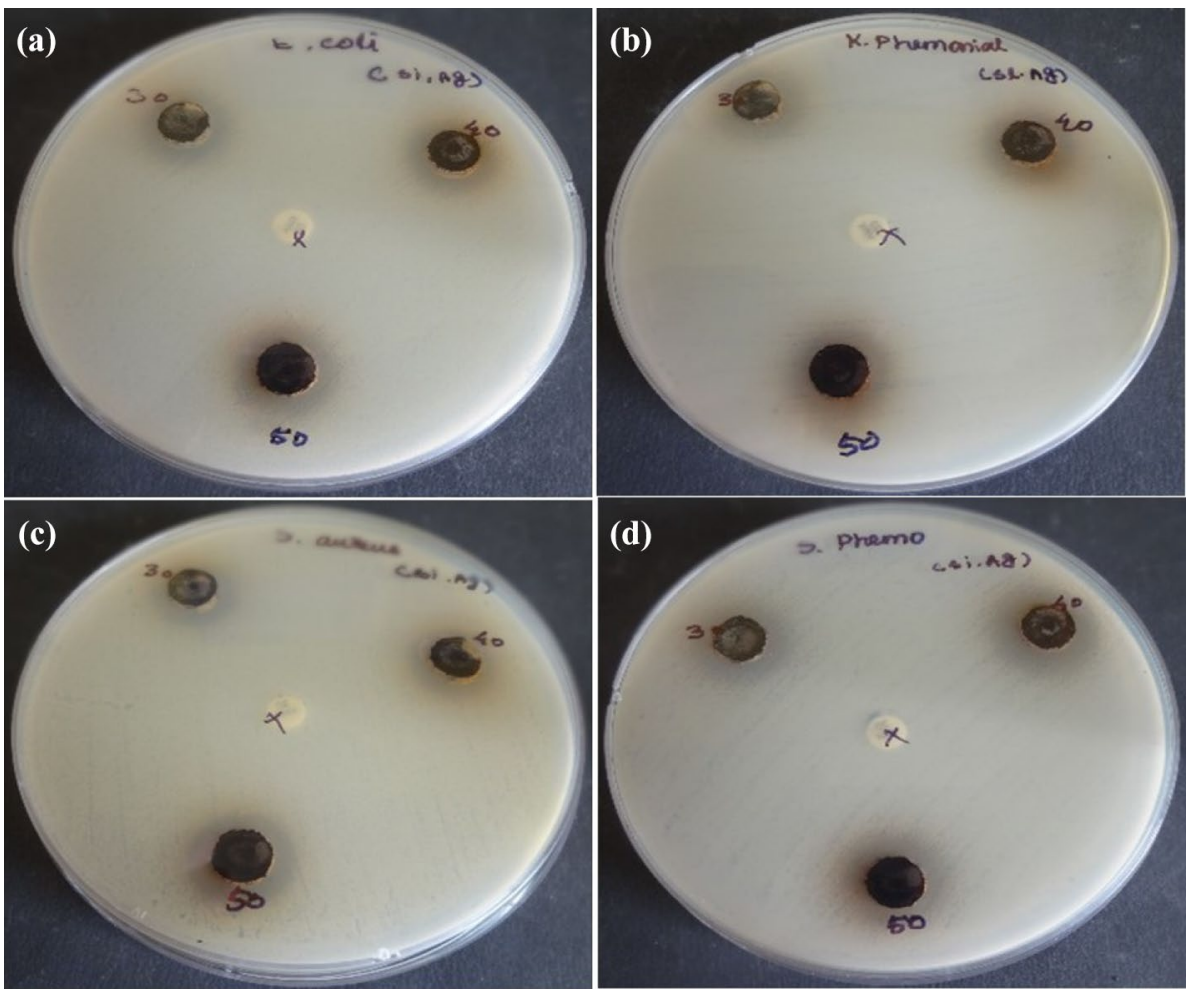

lipids and polysaccharides exhibiting a negative charge, which serves as a weak permeability barrier to the Ag NPs having a positive charge. On the other hand, the Gram-positive bacteria cell wall is composed of a thick and multi peptidoglycan layer comprising of linear polysaccharide chains cross-linked by short peptides to form a three-dimensional rigid structure. This rigid layer, in turn, restricts the attachment or penetration of the Ag NPs to the cell wall $[47,48]$. Finally, antibacterial activity observed (Fig. 10) by increased zone of inhibition against Gram-positive and Gram-negative bacteria depends on the concentration.

The specific mechanism for the antibacterial activity of Ag NPs is still not well established. The interaction of NPs with bacteria often produces reactive oxygen species (ROS), mostly hydroxyl radicals and singlet oxygen, which cause damages to proteins and nucleic acids in bacteria by inducing oxidative stress. It has been proposed that Ag NPs can slowly kill E. coli, K. pneumoniae and S. epidermidis and S. pneumonia leading to the death of the bacteria and these obtained results are higher antibacterial activity when compare to the previous reports [49-52].

\section{Conclusions}

Ag NPs were successfully synthesized by the hydrothermal green synthesis method with the use of aqueous leaf extract of Azadirachta indica A. Juss under the reaction condition. The formation of Ag NPs was confirmed using UV-Visible diffuse reflectance spectroscopy (DRS) absorption peaks at $442 \mathrm{~nm}$ and small band gap (2.1 eV). The PXRD result confirmed that the Ag NPs possessed an fcc crystal structure. In addition, this also revealed that Ag was present in the nanoparticles without any contamination peaks. The TEM images showed that the Ag NPs were in spherical shape and the average diameters of the particles size is $9-15 \mathrm{~nm}$. The antimicrobial activity of silver nanoparticle was excellent as indicated by zone of inhibition against E. coli, K. pneumonia, S. epidermidis and S.pneumonia.To conclude, Ag NPs showed excellent photocatalytic activity of RB in the presence of visible light irradiation.

Acknowledgements Special thanks are due to B.S. Abdur Rahman University, Chennai for providing laboratory facilities to carry out this study. Authors are thankful to the Jamal Mohamed College and KIRND Institute of Research and development-Trichy for providing necessary facilities for the present study. 


\section{References}

1. Jiang ZJ, Liu CY, Sun LW (2005) Catalytic properties of silver nanoparticles supported on silica spheres. J Phys Chem B 109:1730-1735

2. Taleb A, Petit C, Pileni MP (1998) Optical properties of selfassembled 2D and 3D super lattices of silver nanoparticles. J Phys Chem B 102:2214-2220

3. Evanoff DD, Chumanov G (2005) Synthesis and optical properties of silver nanoparticles and arrays. Chem Phys Chem 6:1221-1231

4. Chen D, Qiao X, Qiu X (2009) Synthesis and electrical properties of uniform silver nanoparticles for electronic applications. J Mater Sci 44:1076-1081

5. Bhumkar DR, Joshi HM, Sastry M, Pokharkar VB (2007) Chitosan reduced gold nanoparticles as novel carriers for transmucosal delivery of insulin. Pharm Res 24:1415-1426

6. Ahmad S, Swami M, Ikram L (2015) A review on plants extract mediated synthesis of silver nanoparticles for antimicrobial applications: a green expertise. J Adv Res 7(1):17-28

7. Byrappa K, Adschiri T (2007) Hydrothermal technology for nanotechnology. Prog Cryst Growth Charact Mater 53(2):117-166

8. Hebbalalu D, Lalley J, Nadagouda N, Varma S (2013) Greener techniques for the synthesis of silver nanoparticles using plant extracts, enzymes, bacteria, biodegradable polymers and microwaves. J Chem Eng 7:703-712

9. Kumar M, Reddy GB (2016) Stability-inspired entrapment of Ag nanoparticles in $\mathrm{ZrO}_{2}$ thin films. Plasmonics 11:261-267

10. Kumar M, Jangid T, Panchal V, Kumar P, Pathak A (2016) Effect of grazing angle cross-ion irradiation on Ag thin films. Nanoscale Res Lett 11:454

11. Sun Y, Xia Y (2002) Large-scale synthesis of uniform silver nanowires through a soft, self-seeding, polyol process. Adv Mater 14:833-837

12. Pastoriza-Santos I, Liz-Marzan LM (2002) Formation of PVP-protected metal nanoparticles in DMF. Langmuir 18:2888-2894

13. Rao YN, Banerjee D, Datta A, Das SK, Guin R, Saha A (2010) Gamma irradiation route to synthesis of highly re-dispersible natural polymer capped silver nanoparticles. Radiat Phys Chem 79:1240-1246

14. Kumar B, Angulo Y, Smita K, Cumbal L, Debut A (2018) Capuli cherry-mediated green synthesis of silver nanoparticles under white solar and blue LED light. Particuology. https:// doi.org/10.1016/j.partic.2015.05.005

15. Shameli K, Ahmad MB, Zamanian A, Sangpour P, Shabanzadeh P, Abdollahi Y, Zargar M (2012) Green biosynthesis of silver nanoparticles using Curcuma longa tuber powder. Int J Nanomed 7:5603-5610

16. Danai-Tambhale SD, Adhyapak PV (2014) Facile green synthesis of silver nanoparticles using Psoralea corylifolia L. seed extract and their in vitro antimicrobial activities. Int J Pharm Biol Sci 5:457-467

17. Gnanajobitha G, Paulkumar K, Vanaja M, Rajeshkumar S, Malarkodi C, Annadurai G (2013) Fruit-mediated synthesis of silver nanoparticles using Vitisvinifera and evaluation of their antimicrobial efficacy. J Nanostruct Chem 3:1-6

18. Dewanjee S, Kundu M, Maiti A, Majumdar R, Majumdar A, Mandal SC (2007) In vitro evaluation of antimicrobial activity of crude extract from plants Diospyros peregrina, Coccinia grandis and Swietenia macrophylla trop. J Pharm Res 6:773

19. Bhattacharjee AK, Das AK (1969) Phytochemical survey of few Mysore plants. Econ Bot 23:274-276

20. Nair NC, Henry AN (1983) Flora of Tamil Nadu, India. Series 1 (Analysis), Vol.1: 67 Botanical Survey of India, Coimbatore, India
21. Verma A, Mehata MS (2016) Controllable synthesis of silver nanoparticles using Neem leaves and their antimicrobial activity. J Radiat Res Appl Sci 9:109-115

22. Ahmed S, Ahmad M, Swami BL, Ikram S (2016) Green synthesis of silver nanoparticles using Azadirachta indica aqueous leaf extract. J Radiat Res Appl Sci 9:1-7

23. Namratha N, Monica PV (2013) Synthesis of silver nanoparticles using Azadirachta indica (Neem) extract and usage in water purification. Asian J Pharm Technol 3:170-174

24. Jayaprakash N, Judith Vijaya J, Kaviyarasu K, Kombaiah K, John Kennedy $L$ (2017) Green synthesis of Ag nanoparticles using Tamarind fruit extract for the antibacterial studies. J Photochem Photobiol 169:178-185

25. Lakshmi P, Rao NH, Ruddaraju LK, Kollu P, Soon Gil Y (2017) Green synthesis, characterization and antimicrobial activity of silver nanoparticles using methanolic root extracts of Diospyros sylvatica. JES 55:157-163

26. Roy P, Das B, Mohanty A, Mohapatra S (2017) Green synthesis of silver nanoparticles using Azadirachta indica leaf extract and its antimicrobial study. Appl Nanosci 7:843-850

27. Yan Z, Fu L, Zuo X, Yang H (2018) Green assembly of stable and uniform silver nanoparticles on $2 \mathrm{D}$ silica nanosheets for catalytic reduction of 4-nitrophenol. Appl Catal B 226:23-30

28. Varadavenkatesan T, Selvaraj R, Vinayagam R (2016) Phyto-synthesis of silver nanoparticles from Mussaenda erythrophylla leaf extract and their application in catalytic degradation of methyl orange dye. J Mol Liq 221:1063-1070

29. Rostami-Vartooni A, Nasrollahzadeh M, Alizadeh M (2016) Green synthesis of seashell supported silver nanoparticles using Bunium persicum seeds extract: application of the particles for catalytic reduction of organic dyes. J Colloid Interface Sci 470:268-275

30. Dai R, Chen J, Lin J, Xiao S, Chen S, Deng Y (2009) Reduction of nitro phenols using nitroreductase from $E$. coli in the presence of NADH. J Hazard Mater 170:141-143

31. Naik B, Hazra S, Muktesh P, Prasad VS, Ghosh NN (2011) A facile method for preparation of Ag nanoparticle loaded MCM-41 and study of its catalytic activity for reduction of 4-nitrophenol. Sci Adv Mater 3:1025-1030

32. Ilunga AK, Meijboom R (2016) Catalytic oxidation of methylene blue by dendrimer encapsulated silver and gold nanoparticles. J Mol Catal A Chem 411:48-60

33. Gnanamoorthy $G$, Muthamizh $S$, Sureshbabu $K$, Munusamy $S$, Padmanaban A, Kaaviya A, Nagarajan R, Stephen A, Narayanan $V$ (2018) Photocatalytic properties of amine functionalized $\mathrm{Bi}_{2} \mathrm{Sn}_{2} \mathrm{O}_{7} / \mathrm{rGO}$ nanocomposites. J Phys Chem Solids 118:21-31

34. Ramar K, Vasanthakumar V, Priyadharsan A, Priya P, Raj V, Anbarasan PM, Vasanthakumari R, Jafar Ahamed A (2018) Green synthetic approach of silver nanoparticles from Bauhinia tomentosa Linn. leaves extract for potent photocatalytic and in vitro biological applications. J Mater Sci Mater Electron 29:11509-11520

35. Mukundan D, Vasanthakumari R (2015) Green synthesis of silver nanoparticles using leaves extract of Bauhinia tomentosa Linn and its invitro anticancer potential. Mater Today Proc 7(2):4309-4316

36. Shankar SS, Rai A, Ahmad A, Sastry M (2004) Rapid synthesis of $\mathrm{Au}, \mathrm{Ag}$, and bimetallic $\mathrm{Au}$ core $\mathrm{Ag}$ shell nanoparticles using Neem (Azadirachta indica) leaf broth. J Colloid Interface Sci 275:496-502

37. Xie Y, Ma L, Cheng Z, Yang D, Zhou L, Hao Z (2017) Plasmonassisted site-selective growth of $\mathrm{Ag}$ nanotriangles and $\mathrm{Ag}-\mathrm{Cu}_{2} \mathrm{O}$ hybrids. Sci Rep 1:1-9

38. Anandalakshmi K, Venugobal J, Ramasamy V (2016) Characterization of silver nanoparticles by green synthesis method using Pedalium murex leaf extract and their antibacterial activity. Appl Nanosci 6:399-408 
39. Nadagouda MN, lyanna N, Lalley J, Han C, Dionysiou DD, Varma RS (2014) Synthesis of silver and gold nanoparticles using antioxidants from blackberry, blueberry, pomegranate, and turmeric extracts. Chem Eng 2:1717-1723

40. Chen X, Zheng Z, Ke X, Jaatinen E, Xie T, Wang D, Guo C (2010) Supported silver nanoparticles as photocatalysts under ultraviolet and visible light irradiation. Green Chem 12:414-419

41. Xiao Q, Jaatinen $E$, Zhu H (2014) Direct photocatalysis for organic synthesis by using plasmonic-metal nanoparticles irradiated with visible light. Chem Asian J 9:3046-3064

42. Peiris S, Murtrie JM, Zhu HY (2015) Metal nanoparticle photocatalysts: emerging processes for green organic synthesis. Catal Sci Technol 00:1-3

43. Kumar M, Kumar T, Kumar D (2015) Study of thermal annealing induced plasmonic bleaching in $\mathrm{Ag}$ : $\mathrm{TiO} 2$ nanocomposite thin films. Scr Mater 105:46-49

44. Muthu K, Priya S (2017) Green synthesis, characterization and catalytic activity of silver nanoparticles using Cassia auriculata flower extract separated fraction. Spectrochim Acta A Mol Biomol Spectrosc 179:66-72

45. Sarina S, Waclawik ER, Zhu H (2013) Photocatalysis on supported gold and silver nanoparticles under ultraviolet and visible light irradiation. Green Chem 15:1814-1833

46. Aziz N, Faraz M, Pandey R, Shakir M, Fatma T, Varma A, Barman I (2015) Facile algae-derived route to biogenic silver nanoparticles: synthesis, antibacterial, and photocatalytic properties. Langmuir 31:11605-11612
47. Gnanamoorthy G, Dhanasekaran T, Munusamy S, Padmanaban A, Stephen A, Narayanan V (2018) Photocatalytic and biological properties of porous titanium aminophosphate. Appl Nanosci 8:1791-1807

48. Kahrilas GA, Haggren W, Read RL, Wally LM, Fredrick SJ, Hiskey M, Prieto AL, Owens JE (2014) Investigation of antibacterial activity by silver nanoparticles prepared by microwave-assisted green syntheses with soluble starch, dextrose, and arabinose. Chem Eng 2:590-598

49. Javid A, Kumar M, Yoon S, Lee H (2017) Size-controlled growth and antibacterial mechanism for $\mathrm{Cu}$ : $\mathrm{C}$ nanocomposite thin films. Phys Chem Chem Phys 19:237-244

50. Tiwari V, Khokar MK, Tiwari M, Barala S, Kumar M (2014) Antibacterial activity of polyvinyl pyrrolidone capped silver nanoparticles on the carbapenem resistant strain of Acinetobacter baumannii. J Nanomed Nanotechnol 5:240-246

51. Sivaranjan K, Vanitha P, Sathiyaseelan A, Kalaichelvan PT, Sathuvan M, Rengasamy R, Santhanalakshmi J (2017) Insights into the catalytic reduction of organic dyes and antibacterial activity of graphene oxide supported mono and bimetallic nanocomposites. New J Chem 41:4348-4359

52. Varun Prasath $P$, Ravichandran K, Sankara Narayanan T, Nellaiappan S (2018) New core shell hydroxyapatite/gum acacia nanocomposites for drug delivery and tissue engineering applications. Mater Sci Eng 92:685-693 